\title{
Wintertime Temperature Variability over Kingdom of Saudi Arabia
}

\author{
A.K. Al-Khalaf, and H.M. Hasanean \\ Department of Meteorology \\ Faculty of Meteorology, Environment, and Arid Land Agriculture, \\ King Abdulaziz University, Jeddah, Saudi Arabia
}

\begin{abstract}
Mean wintertime temperature (December, January, February) recorded at 26 weather stations distributed across Kingdom of Saudi Arabia (KSA) were analyzed to reveal spatial and temporal patterns of long-term trends. The behavior of wintertime temperature since 1979 is examined with regard to the persistence, non-linear trends and inter-decadal variations. The coefficient of variability $(\mathrm{COV})$ of winter temperature decreases gradually from north to south of KSA. The higher values of COV occur north and northeast of KSA. The higher values of winter COV over north and north east of KSA is due to the effect of the Traveling Mediterranean depressions and its interaction with the inverted-V shape trough of the Sudan low. Relationship between COV and latitudes is highly significant, while with longitudes is not significant. The Mann-Kendal statistical rank test illustrates that positive trends (warming) in winter temperature series occur over the all stations and the trends are significant at mid and southern region of the KSA. Recent warming has only occurred during the last two decades at most stations. While cooling in wintertime surface temperature appears for the short period of about 5 years, 1979-1983 and 1988-1993. These trends are in general consistence with trends in the global mean surface temperature.
\end{abstract}

Keywords: Winter temperature, coefficient of variability, trends, Kingdom Saudi Arabia.

\section{Introduction}

Although global warming may have already triggered abrupt change, current understanding and modeling capability is not sufficient to specify 
details of future abrupt climate change. Many researchers (Li, 2001, Yan et al., 2001, 2003 and Zhao et al., 2008) investigated the trend of climate variables and the characteristics of the climate abrupt changes. Winter air temperature is an issue of great concern, since their variability and extremes have important economical and social implications. Humaninduced climate change and changes in climatic variability continue to be major global change issues not only for the present generation but also for future generations. Based on the latest scientific assessment of the Earth's climate system, Folland et al., (2001) have revealed that average global surface temperature has increased by about $0.6 \pm 0.2^{\circ} \mathrm{C}$ since the late 19th century. The Northern Hemisphere experienced cooling during the period from 1946 to 1975 . They pointed out that the recent 19762000 warming was largely globally synchronous, but was more pronounced in the Northern Hemisphere continents during winter and spring.

One aspect of climate change is change in variability of weather elements, such as temperature. Adaptation to climate change and efforts to mitigate the impacts of climate change need to emphasize not only changes in long-term mean weather attributes but also trends in the variability of climatic variables (Bryant et al., 2000). Given that climatic conditions vary from one period to another, variability is an integral part of climate change. Consequently, response strategies and adaptations to climatic change, both at the regional and global levels, must address climatic variability. According to Giorgi (2002), the impact of climatic variability on human and natural systems is more important than that of mean changes in climate.

In this work, the behavior of wintertime temperature over KSA since 1979 is examined with regard to the persistence, non-linear trends and inter-decadal variations. Observation data set and homogeneity are described in sections 2 and sections 3 respectively. Section 4 describes the methods that were used, while section 5 contains the results and discussion of studying the winter temperature changes and variability over KSA. Finally conclusion is appended in Section 6.

\section{The Climatic Characteristics of KSA}

KSA is characterized by complex topographical surface and cover vast area (approximately 2,250,000 km2), occupies nearly eighty percent 
of the Arabian Peninsula. KSA stretches from $15.5^{\circ} \mathrm{N}$ to $32.5^{\circ} \mathrm{N}$ in latitude and from $32^{\circ} \mathrm{E}$ to $55^{\circ} \mathrm{E}$ in longitude (Fig. 1). The country is characterized by distinct climatic regions, due to high spatial and temporal temperature variability. In addition, the temperature distribution of the observed dataset is also characterized by high inter-annual variability (Al Mazroui, et al., 2009). KSA region has received little attention, despite the fact that Mediterranean and adjacent regions have been widely explored during the last few decades (Reiter, 1975; Hoskins and Pedder, 1980; Lee et al., 1988 and Trigo et al., 2002). In general, most of the country can be classified as arid land (extreme desert and true desert) and semi-arid (semi-desert) ecosystems (Shmida, 1985). KSA is one of the driest subcontinents in the world (Schyfsma, 1978) characterized by unpredictable and low-erratic precipitation and high temperatures with the exception of the province of Asir with its towns of Jazan on the western coast and Najran, Saudi Arabia has a desert climate characterized by extreme heat during the day, an abrupt drop in temperature at night, and slight, erratic rainfall. Because of the influence of a subtropical high-pressure system and the many fluctuations in elevation, there is considerable variation in temperature and humidity. Along the coastal regions of the Red Sea and the Arabian Gulf, the desert temperature is moderated by the proximity of these large bodies of water. Temperatures seldom rise above $38^{\circ} \mathrm{C}$, but the relative humidity is usually more than 85 percent and frequently 100 percent for extended periods. This combination produces a hot mist during the day and a warm fog at night. Prevailing winds are from the north, and, when they blow, coastal areas become bearable in the summer and even pleasant in winter. A southerly wind is accompanied invariably by an increase in temperature and humidity and by a particular kind of storm known in the gulf area as a kauf. In late spring and early summer, a strong northwesterly wind, the shamal, blows; it is particularly severe in eastern Arabia and continues for almost three months. The shamal produces sandstorms and dust storms that can decrease visibility to few meters.

\section{KSA Meteorological Stations Data}

Monthly mean surface temperatures for the twenty six stations were obtained from the Presidency of Meteorology and Environment in KSA (Fig. 1). The selection of these stations is based on their quality and the length of their records. The beginning and end of all time series are the 
year of 1979 and 2006 respectively except Ahsa, Baha, Guriat, Makkah, and Sharura station beginning at 1985 and Hafrbaten beginning at 1990 (Table 1). From the monthly values of each station, the wintertime series by averaging the values of surface temperature of the months December, January, and February were calculated for each year. The stations under study are distributed all over KSA, although their spatial density is low and uneven over some parts of the country. Table 1 and Fig. 1 illustrate the name, the position, the elevation and the available period of each of KSA meteorological stations.

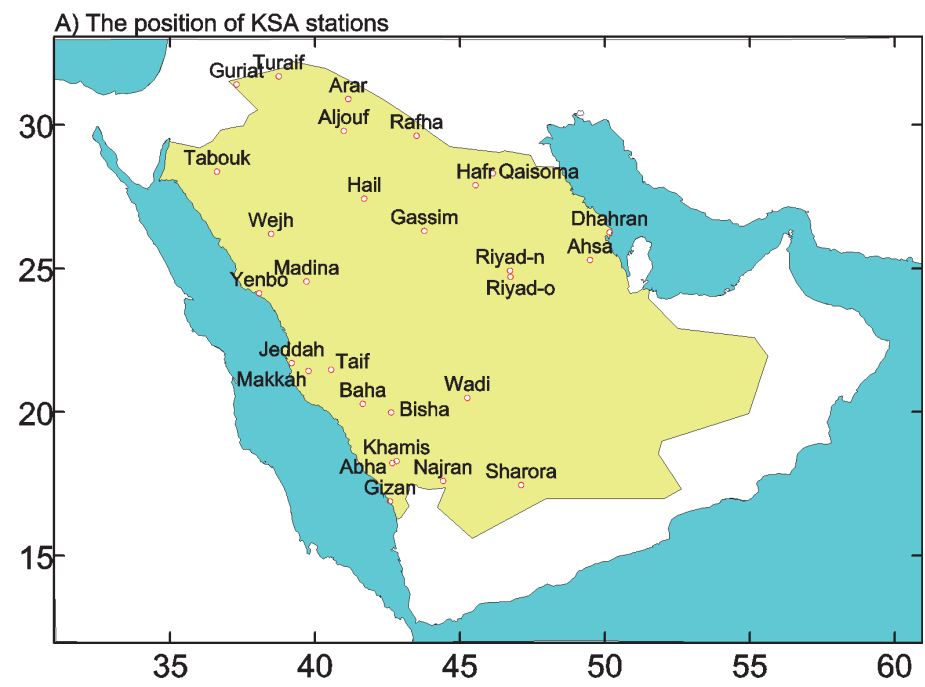

Fig. 1: The name and position of KSA stations.

Table 1. KSA stations, location and record.

\begin{tabular}{|c|l|c|c|c|c|c||}
\hline \hline No & Name & Latitude & Longitude & Elevation & Available Data & Years \\
\hline 1 & Turaif & 31.68 & 38.73 & 852.44 & $1978-2008$ & 32 \\
\hline 2 & Gurait & 31.40 & 37.28 & 503.90 & $1985-2008$ & 26 \\
\hline 3 & Arar & 30.90 & 41.14 & 548.88 & $1978-2008$ & 32 \\
\hline 4 & Aljouf & 29.78 & 40.98 & 668.74 & $1978-2008$ & 28 \\
\hline 5 & Rafha & 29.62 & 43.49 & 413.00 & $1978-2008$ & 28 \\
\hline 6 & Tabouk & 28.37 & 36.60 & 444.10 & $1978-2008$ & 28 \\
\hline 7 & Alqaisoma & 28.31 & 46.13 & 1001.52 & $1978-2008$ & 28 \\
\hline 8 & Hail & 27.43 & 41.69 & 768.11 & $1978-2008$ & 28 \\
\hline 9 & Gassim & 26.30 & 43.76 & 178.17 & $1978-2008$ & 28 \\
\hline 10 & Dhahran & 26.25 & 50.16 & 16.77 & $1978-2008$ & 28 \\
\hline 11 & Alwajh & 26.20 & 38.47 & 357.60 & $1978-2008$ & 28 \\
\hline 12 & Ahsa & 25.29 & 49.48 & 23.73 & $1985-2006$ & 22 \\
\hline 13 & Riyadh & 24.92 & 46.72 & 613.55 & $1978-2008$ & 28 \\
\hline 14 & Madina & 24.54 & 39.69 & 3.58 & $1978-2008$ & 28 \\
\hline
\end{tabular}




\begin{tabular}{||c|l|c|c|c|c|c||}
\hline \hline No & Name & Latitude & Longitude & Elevation & Available Data & Years \\
\hline 15 & Yenbo & 24.14 & 38.06 & 1452.75 & $1978-2008$ & 28 \\
\hline 16 & Jeddah & 21.71 & 39.18 & 240.35 & $1978-2008$ & 28 \\
\hline 17 & Taif & 21.48 & 40.55 & 614.39 & $1978-2008$ & 22 \\
\hline 18 & Makkah & 21.43 & 39.79 & 701.02 & $1985-2008$ & 22 \\
\hline 19 & Baha & 20.29 & 41.64 & 1651.88 & $1985-2008$ & 22 \\
\hline 20 & Bisha & 19.99 & 42.61 & 1161.97 & $1985-2008$ & 28 \\
\hline 21 & Khamis - Mushet & 18.29 & 42.80 & 2093.35 & $1978-2008$ & 28 \\
\hline 22 & Abha & 18.23 & 42.66 & 2055.93 & $1978-2008$ & 28 \\
\hline 23 & Najran & 17.61 & 44.41 & 1212.33 & $1978-2008$ & 28 \\
\hline 24 & Sharura & 17.46 & 47.10 & 724.65 & $1985-2008$ & 22 \\
\hline 25 & Jazan & 16.90 & 42.58 & 7.24 & $1978-2008$ & 28 \\
\hline \hline
\end{tabular}

\section{Homogeneity}

Lack of homogeneity in data series creates a big problem for studying time series. A time series of a climatological variable where the variations are caused by variations of weather and climate only is said to be homogeneous (Conrad and Pollack, 1962). However, long time series without artificial changes in their statistical characteristics are rare (e.g. Heino, 1994). Non-homogeneities may be abrupt, caused by relocations of instruments or changes of instruments, observers and observation practices, etc. Slow changes of the surroundings of the observation site may cause non-homogeneities to be gradual, e.g. in the case of urbanization. The timing and size of significant non-homogeneities can be estimated with statistical tests. The authors used the short-cut Bartlett test (Mitchell et al., 1966) to examine the homogeneity of the surface air temperature series at designated stations. The short-cut Bartlett test of homogeneity of variance for winter air temperature is applied by dividing the series into $k$ equal sub-periods, where $k \geq 2$. In each of these subperiods the sample variance is calculated, i.e; $S_{k}=\frac{1}{n}\left\{\sum x_{i}-\frac{1}{n}\left(\sum x_{i}\right)^{2}\right\}$. Where the summations range over the $n$ values of the series in the subperiod $k$. Let $S_{\max }^{2}$ and $S_{\min }^{2}$ denotes the maximum and the minimum of the values of $S_{k}^{2}$, respectively. The $95 \%$ significance points ratio $S_{\max }^{2} / S_{\min }^{2}$ can be obtained by comparing this ratio with the values given in Biometrika Table 31 (Pearson and Hartley, 1958). All time series used are found to be homogeneous as shown in Table 2. 
Table 2. Bartlet test (short-cut) result for the KSA stations ( $n$ is the number of terms in each subperiod $k$, and $k$ is the number of the subperiod).

\begin{tabular}{||l|c|c|c|c|c||}
\hline \hline Station & Period & $\mathbf{N}$ & $\mathbf{K}$ & 95\% Significant point & Homogenity \\
\hline Turaif & 28 & 14 & 2 & 3.24 & 1.03 \\
\hline Guriat & 22 & 11 & 2 & 3.72 & 0.76 \\
\hline Arar & 28 & 14 & 2 & 3.24 & 1.00 \\
\hline Aljouf & 28 & 14 & 2 & 3.24 & 0.96 \\
\hline Rafha & 28 & 14 & 2 & 3.24 & 0.98 \\
\hline Tabouk & 28 & 14 & 2 & 3.24 & 1.05 \\
\hline Alqaisoma & 28 & 14 & 2 & 3.24 & 0.95 \\
\hline Hafrbaten & 17 & 9 & 2 & 4.43 & 2.63 \\
\hline Hail & 28 & 14 & 2 & 3.24 & 1.04 \\
\hline Gassim & 28 & 14 & 2 & 3.24 & 1.02 \\
\hline Dhahran & 28 & 14 & 2 & 3.24 & 1.06 \\
\hline Alwajh & 28 & 14 & 2 & 3.24 & 1.10 \\
\hline Ahsa & 22 & 11 & 2 & 3.72 & 1.06 \\
\hline Riyadh - Nnew & 28 & 14 & 2 & 3.24 & 1.06 \\
\hline Madinah & 28 & 14 & 2 & 3.24 & 1.18 \\
\hline Yanbo & 28 & 14 & 2 & 3.24 & 1.16 \\
\hline Jeddah & 28 & 14 & 2 & 3.24 & 1.11 \\
\hline Taif & 22 & 11 & 2 & 3.72 & 1.08 \\
\hline Makkah & 22 & 11 & 2 & 3.72 & 0.82 \\
\hline Baha & 22 & 11 & 2 & 3.72 & 0.87 \\
\hline Bisha & 28 & 14 & 2 & 3.24 & 0.89 \\
\hline Khamis - Moshet & 28 & 14 & 2 & 3.24 & 1.07 \\
\hline Abha & 28 & 14 & 2 & 3.24 & 1.08 \\
\hline Najran & 28 & 14 & 2 & 3.24 & 0.88 \\
\hline Sharurah & 22 & 11 & 2 & 3.72 & 1.02 \\
\hline Jazan & 28 & 14 & 2 & 3.24 & 0.98 \\
\hline \hline
\end{tabular}

\section{Methodology}

A coefficient of variation $(\mathrm{COV})$ for each individual station has been determined as follows: $C O V=100 * S D / \mu$. Where, SD is the standard deviation and $\mu$ is the temporal mean for $N$ years.

The evaluation of the trend analysis is based on the Hu et al., (1998) method. The 11-yr running mean is a filtering method. It removes variations with periods shorter than $10-\mathrm{yr}$ in a time series and retains variations of inter-decadal timescales, which are the focus of this study. The symmetry of the weight distribution guarantees no phase shift of the variations in the time series after the filter is applied. The response function of the running mean is similar to that of an ordinary filter, for example, Shapiro 1975. And it has small effect on variations whose 
frequencies are lower than the cutoff frequency of the filter but has large effects on variations of frequency near its cutoff frequency, for example, the 12 -yr variation.

The non-parametric Mann-Kendall (M-K) statistical test (Sneyers, 1990; Schonwiese and Rapp, 1997 and Hasanean, 2004) has been used to detect any possible trend in temperature series, and to test whether or not such trends are statistically significant. A detailed assessment for testing of climatic data unevenly distributed in time and a comparison of methods for estimating the significance level of any trend can be found in a study performed by Huth (1999). The M-K statistical test is a value that indicates direction (or sign) and statistical magnitude of the trend in a series.

\section{Results and Discussion}

\section{Coefficient of Variation (COV)}

After our examination of abrupt change for the wintertime surface temperature, we will examine the coefficient of variation. The COV of wintertime temperature is displayed in Table 3. The COV of winter temperature decreases gradually from north to south of KSA. The higher values of COV occur north and northeast of KSA with the highest one at Turaif (13.4\%), the northern station of KSA. While the lowest value of COV of winter appears at Jazan (1.9\%), the southern station in KSA. The higher values of winter COV over north and north east of KSA is due to the effect of the Traveling Mediterranean depressions and its interaction with the inverted- V shape trough of the Sudan low.

Table 3 illustrates also that the COV ranged from $1.9 \%$ at Jazan to $13.4 \%$ at Turaif and the average of the COV of summer temperature is usually about $6 \%$. The higher and lower values of the standard deviations (SD) are associated with the higher and lower values of the COV (Table $3)$. Generally, the COV of winter temperature is high. Therefore the winter temperature is less stable over KSA.

The relationship between $\mathrm{COV}$ and latitude is positive and high significant $(\mathrm{r}=0.8,99 \%$ significant level) while it is negative and not significant with longitude $(\mathrm{r}=-0.24)$. So, the COV values increase with increasing latitude (the values of COV at the north stations are more than those at the south) and increase with decreasing longitudes (the values of 
$\mathrm{COV}$ at the west stations are more than those at the east). This result is reasonable in winter season where the north of KSA has considerable difference of temperature than in the south while the difference in temperature from west to east is small.

Table 3. The standard deviation, mean and coefficient of variation of winter temperature for KSA stations.

\begin{tabular}{||l|c|c|c|c|c||}
\hline Station & Latitude & Longitude & SD & MEAN & COV \\
\hline Turaif & 31.68 & 38.73 & 1.11 & 8.34 & 13.4 \\
\hline Guriat & 31.40 & 37.28 & 1.00 & 9.56 & 10.4 \\
\hline Arar & 30.90 & 41.14 & 1.15 & 9.96 & 11.5 \\
\hline Aljouf & 29.78 & 40.98 & 1.33 & 10.70 & 12.4 \\
\hline Rafha & 29.62 & 43.49 & 1.18 & 11.48 & 10.3 \\
\hline Tabouk & 28.37 & 36.60 & 1.15 & 11.94 & 9.6 \\
\hline Alqaisoma & 28.31 & 46.13 & 1.21 & 13.02 & 9.3 \\
\hline Hafrbaten & 27.90 & 45.53 & 0.80 & 25.20 & 3.2 \\
\hline Hail & 27.43 & 41.69 & 1.21 & 11.69 & 10.3 \\
\hline Gassim & 26.30 & 43.76 & 1.23 & 13.99 & 8.8 \\
\hline Dhahran & 26.25 & 50.16 & 0.96 & 16.59 & 5.8 \\
\hline Alwajh & 26.20 & 38.47 & 0.93 & 19.74 & 4.7 \\
\hline Ahsa & 25.29 & 49.48 & 0.88 & 16.23 & 5.5 \\
\hline Riyadh-New & 24.92 & 46.72 & 1.07 & 15.87 & 6.8 \\
\hline Madinah & 24.54 & 39.69 & 1.19 & 19.15 & 6.2 \\
\hline Yanbo & 24.14 & 38.06 & 1.13 & 21.31 & 5.3 \\
\hline Jeddah & 21.71 & 39.18 & 0.89 & 23.66 & 3.8 \\
\hline Taif & 21.48 & 40.55 & 0.83 & 16.29 & 5.1 \\
\hline Makkah & 21.43 & 39.79 & 0.99 & 24.62 & 4.0 \\
\hline Baha & 20.29 & 41.64 & 0.71 & 16.55 & 4.3 \\
\hline Bisha & 19.99 & 42.61 & 0.99 & 18.64 & 5.3 \\
\hline Khamis-Moshet & 18.29 & 42.80 & 0.86 & 14.65 & 5.9 \\
\hline Abha & 18.23 & 42.66 & 0.57 & 13.81 & 4.1 \\
\hline Najran & 17.61 & 44.41 & 0.95 & 18.45 & 5.1 \\
\hline Sharurah & 17.46 & 47.10 & 0.89 & 20.77 & 4.3 \\
\hline Gizan & 16.90 & 42.58 & 0.51 & 26.38 & 1.9 \\
\hline & & & & & \\
\hline
\end{tabular}

\section{Trend Analysis}

The wintertime temperature series for the KSA stations under study have been investigated to determine their trends. The studies of trends have been performed by means of both a simple and sophisticated tools.

The evaluation of the trend is based on the Mann-Kendall (M-K) statistical test. Mann-Kendall (M-K) statistical test, which make no assumption about probability distribution for the original data, are tested for significance using a standard normal distribution. The spatial distribution pattern is not complex, even though the resultant test 
statistics M-K test give both negative and positive trends. Table 4 and Fig. 2 show the Mann-Kendall statistics for the 26 sites in KSA. The values of $\mathrm{M}-\mathrm{K}$ statistical test were computed according to Sneyers (1990). Positive trends (warming) are observed over all stations. Table 4 and Fig. 2 indicate that the trend is high and significant in the southern and middle regions stations. The values of the Mann-Kendall statistic that is significantly different from zero at the $5 \%$ and/or $1 \%$ level.

Table 4. The trend values of the winter temperature of KSA stations by Mann- Kendall rank correlation test.

\begin{tabular}{||l|c|c|c|}
\hline \hline Station & Latitude & Longitude & Trend \\
\hline Turaif & 31.68 & 38.73 & 0.10 \\
\hline Guriat & 31.40 & 37.28 & 0.10 \\
\hline Arar & 30.90 & 41.14 & 0.10 \\
\hline Aljouf & 29.78 & 40.98 & 0.17 \\
\hline Rafha & 29.62 & 43.49 & 0.10 \\
\hline Tabouk & 28.37 & 36.60 & 0.10 \\
\hline Qaisoma & 28.31 & 46.13 & 0.18 \\
\hline Hafrbaten & 27.90 & 45.53 & 0.13 \\
\hline Hail & 27.43 & 41.69 & $0.27^{*}$ \\
\hline Gassim & 26.30 & 43.76 & 0.20 \\
\hline Dhahran & 26.25 & 50.16 & $0.33^{* *}$ \\
\hline Alwajh & 26.20 & 38.47 & 0.18 \\
\hline Ahsa & 25.29 & 49.48 & 0.10 \\
\hline Riyad-New & 24.92 & 46.72 & 0.20 \\
\hline Madinah & 24.54 & 39.69 & 0.21 \\
\hline Yanbo & 24.14 & 38.06 & 0.21 \\
\hline Jeddah & 21.71 & 39.18 & 0.10 \\
\hline Taif & 21.48 & 40.55 & $0.27^{*}$ \\
\hline Makkah & 21.43 & 39.79 & $0.27^{*}$ \\
\hline Baha & 20.29 & 41.64 & $0.46^{* *}$ \\
\hline Bisha & 19.99 & 42.61 & $0.35^{* *}$ \\
\hline Khamis-Moshet & 18.29 & 42.80 & $0.70^{* *}$ \\
\hline Abha & 18.23 & 42.66 & $0.46^{* *}$ \\
\hline Najran & 17.61 & 44.41 & $0.31^{*}$ \\
\hline Sharurah & 17.46 & 47.10 & 0.15 \\
\hline Gizan & 16.90 & 42.58 & $0.41^{* *}$ \\
\hline
\end{tabular}

An insight to the results achieved by means of $\mathrm{Hu}$ et al., (1998) method (dotted curve, thin curve). Persistent phases of alternating increase or decrease of the temperature, which vary in length, are recognizable in the time series of the winter temperature. Fig. 2 illustrates the behavior of temperature during the available data period of each station. Fig. 2 gives evidence that from the first period under study up to 1983 an important decrease of surface temperature occurs at all stations. 
The decrease in mean winter surface temperature reached about $1{ }^{\circ} \mathrm{C}$ but it was not uniform at all areas under investigation. Also another important decrease of more than $1{ }^{\circ} \mathrm{C}$ appeared at all stations round 1987 and/or 1988. Our results revealed that increasing of wintertime surface temperature (warming) of the most stations has existed in the last two decades beginning around 1993 and/or 1994 and continued up to the end of the period under study. Also, an important increase of surface temperature in southern region (Bisha, Khamis-Moshet, Abha, Najran, Sharurah and Gizan stations) from 1984 up to the end of the period under study (2006). These trends are in general consistence with trends in the global mean surface temperature since the late 19th century. The most probable cause of the observed warming in recent climate change is a combination of internally and externally forced natural variability and anthropogenic sources.
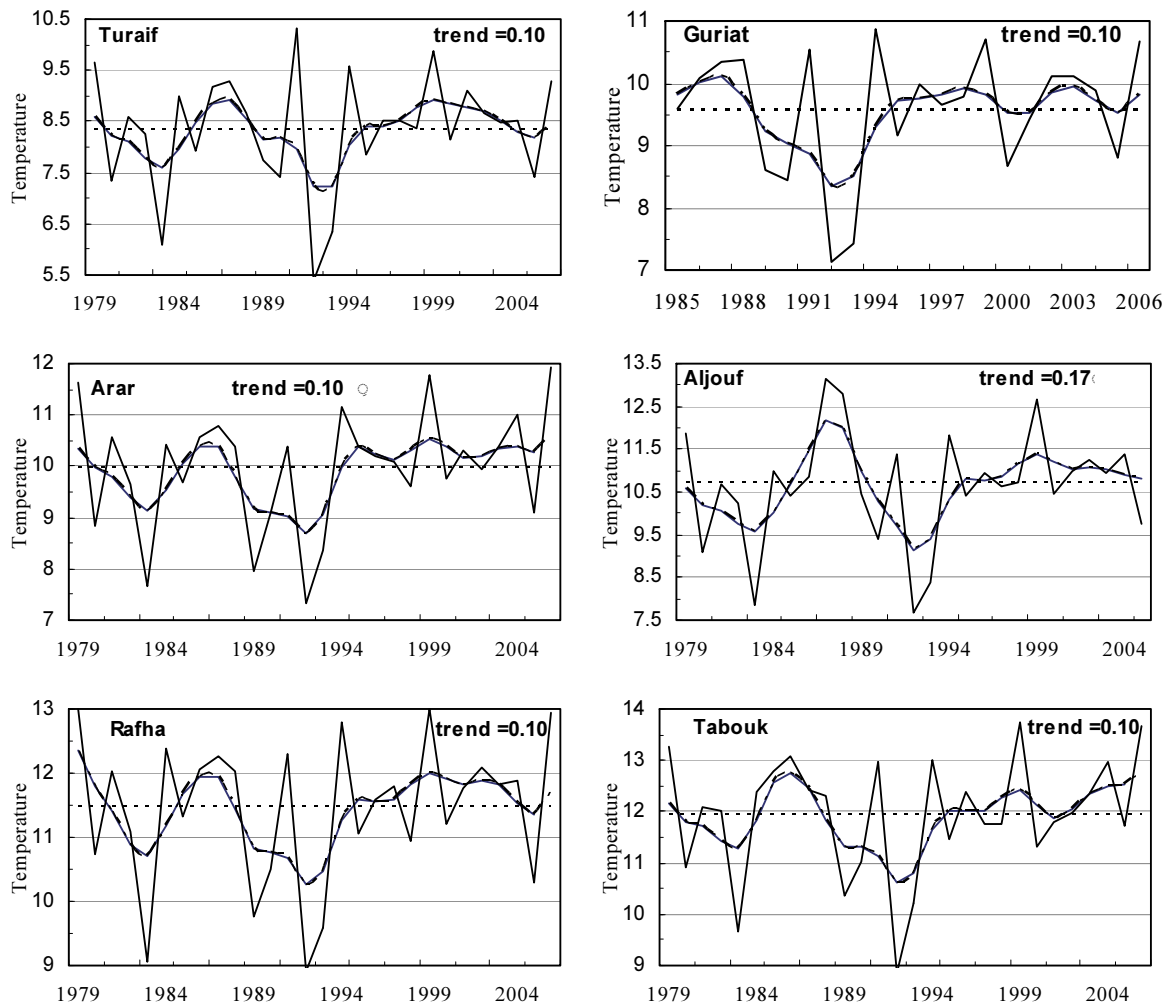

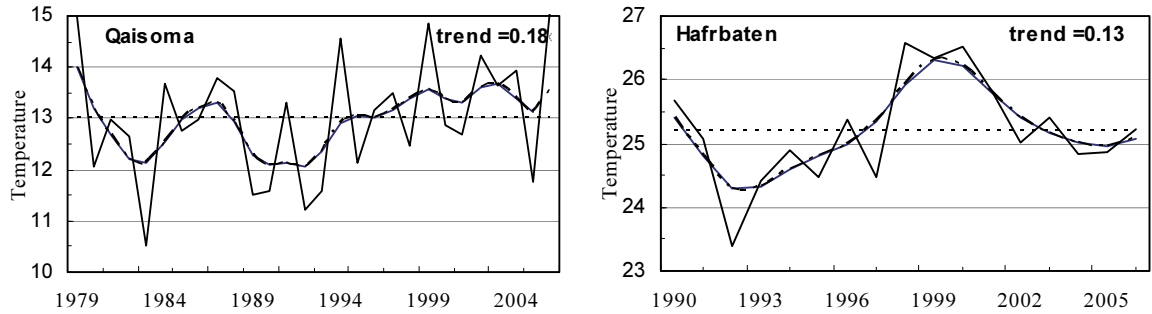

Fig. 2a. Trend analysis of the winter surface temperature of the stations Turaif, Guriat, Arar, Aljouf, Rafha, Tabouk, Alqaisoma, Hafrbaten, Hail and Gassim, (dotted line is the mean, dotted smoothed curve is a trend, solid curve is the observation data.
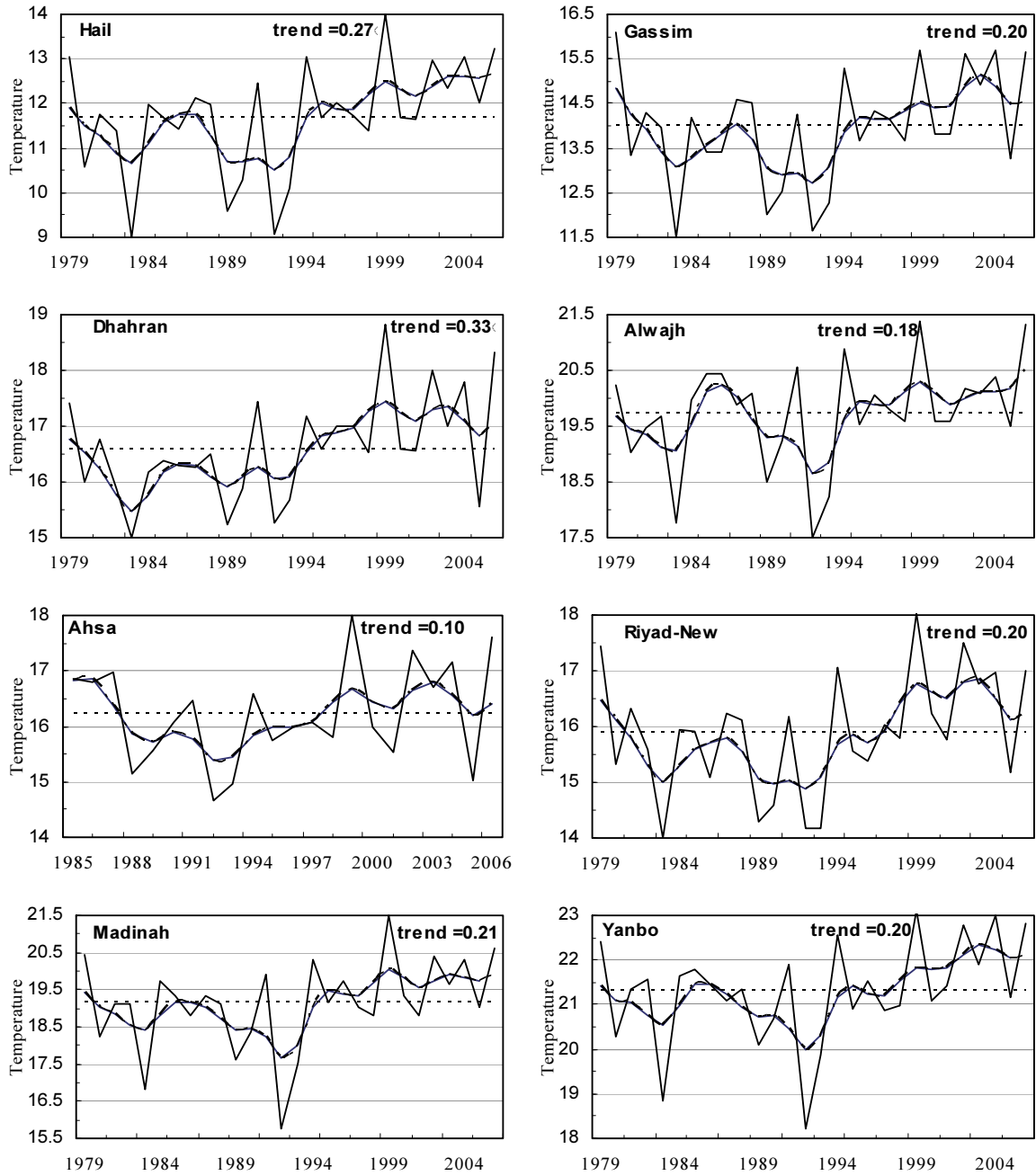

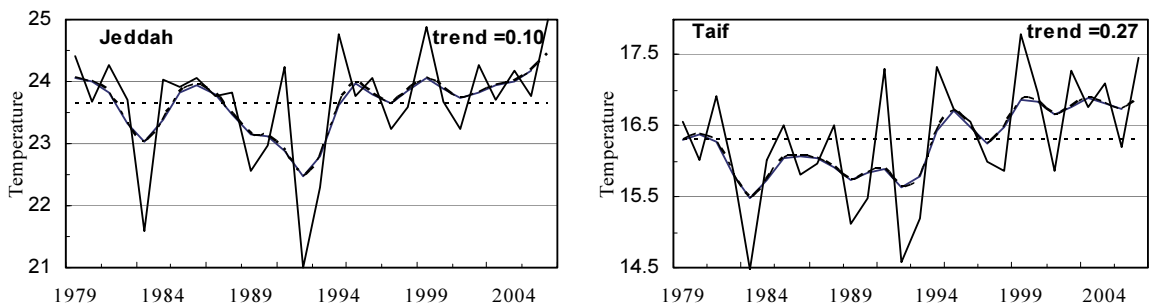

Fig. 2b. As in Figure 2a but for the stations Dhahran, Alwajh, Ahsa, Riyadh new, Madinah, Yanbo, Jeddah, Taif, Makkah and Baha.
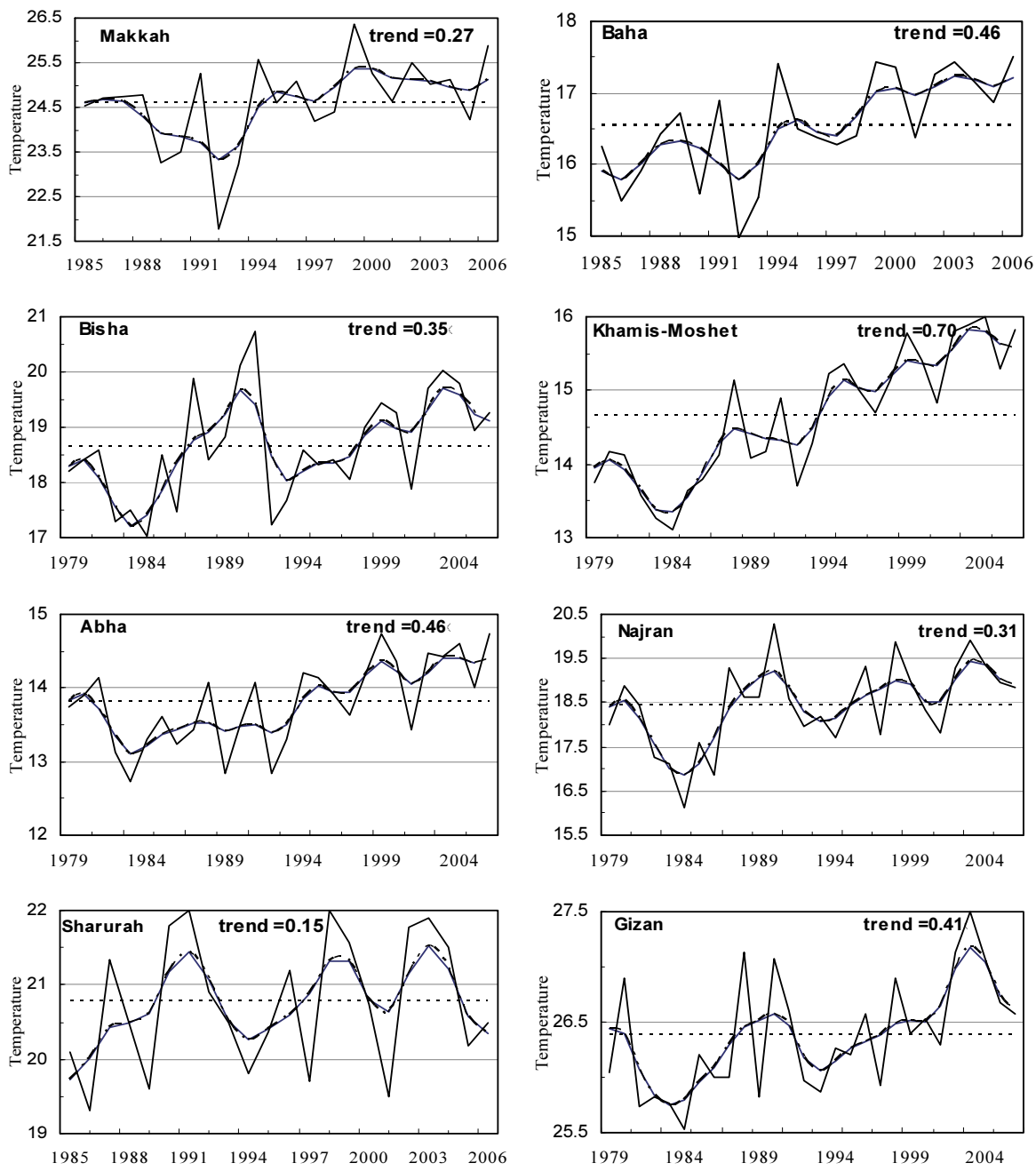

Fig. 2c. As in Figure 2a but for the stations Bisha, Khamis- Mushet, Abha, Najran, Sharura and Jazan. 


\section{Conclusions}

Changes in the winter temperature over KSA have been investigated throughout the available data period of twenty six stations. In order to get a clear and representative picture of winter temperature in KSA, the coefficient of variation (COV) is adopted to assess the durability and stability of the temperature in different regions of KSA. We found that the COV of winter temperature over KSA ranged from $1.9 \%$ to 13.4 , and it was usually about $6 \%$. Also we found that the reason of the spatial variations of $\mathrm{COV}$ is due to the effect of the Traveling Mediterranean depressions and its interaction with the inverted- V shape trough of the Sudan low. Relationship between COV and latitudes is highly significant, while with longitudes is not significant. Mann-Kendall (M-K) rank correlation test illustrates that positive trends (warming) in winter temperature series occurs over the all stations and the trends of winter temperature are significant at mid and southern region of the KSA.

The use of $\mathrm{Hu}$ et al., (1998) method for surface temperature is a worthwhile approach to studying inter-annual climate fluctuations, because they reveal time varying structure in the raw data or in the more traditional statistical analyses. Examination of the $\mathrm{Hu}$ et al., (1998) method winter temperature over KSA has revealed support for the notion of extended "persistence" over several years, even though simple year-toyear persistence may be evident. The wintertime temperature of the area is characterized by warm periods 1993-2006 at all regions of KSA stations, and 1984-2006 in southern region stations. While cooling in the wintertime surface temperature appeared for the short period of about 5 years, 1979-1983 and 1988-1993. A warm period was not uniform, continuous or of the same order. Recent warming has only occurred during the last two decades at most stations. These trends are in general consistence with trends in the global mean surface temperature especially since the late 19th century. The most probable cause of the observed warming in recent climate change is a combination of internally and externally forced natural variability and anthropogenic sources.

\section{Acknowledgements}

The authors are grateful for being enabled to use monthly mean KSA station temperature series from the KSA Meteorological Authority. We are indebted to the faculty of meteorology and environment, for making available the computer and other facilities in this work. 


\section{References}

Almazroui, M.A., Al Khalaf, A.K., Abdel Basset H.M. and Hasanean H.M. (2009). Detecting Climate Change Signals in Saudi Arabia Using Surface Temperature. Project number (305/428) is supported from King Abdelaziz University, Kingdom of Saudi Arabia.

Bryant, C.R., Smit, B., Brklacich, M., Johnston, T.R., Smithers, J., Chiotti, Q. and Singh, B. (2000). Adaptation in Canadian agriculture to climatic variability and change. Climate Change 45: 181-201.

Conrad, V. and Pollack, C. (1962). Methods in climatology, Harvard University Press, Cambridge, MA, 459 pp.

Folland, C.K., Karl, T.R., Christy, J.R., Clarke, R.A., Gruza, G.V., Jouzel, J., Mann, M.E., Oerlemans, J., Salinger, M.J. and Wang, S.W. (2001). Observed climate variability an change In Climate Change 2001: The Scientific Basis. Contribution of Working Group I to the Third Assessment Report of the Intergovernmental Panel on Climate Change, Houghton JT, Ding Y, Griggs DJ, Noguer M, van de Linden PJ, Dai X, Maskell K, Johnson CA (eds). Cambridge University Press: Cambridge; 99-181.

Giorgi, F. (2002). Variability and trends of sub-continental scale surface climate in the twentieth century. Part I: observations. Climate Dynamic 18: 693-708.

Hasanean, H.M. (2004). Wintertime surface temperature in Egypt in relation to the associated atmospheric circulation. International Journal of Climatology 24, 985-999.

Heino, R. (1994). Climate in Finland during the Period of Meteorological Observations, Finnish Meteorological Institute Contributions 12, Academic dissertation, Helsinki, 209 pp.

Hoskins, B.J. and Pedder, M.A. (1980). The diagnosis of middle latitude synoptic development. Quart J Roy Meteor Soc 106: 707-719.

Hu, Q., Woodruff, C.M. and Mudrick, S.E. (1998). Interdecadal Variations of Annual Precipitation in the Central United States, Bulletin of the American Meteorological Society, 79(2): 221-229.

Huth, R. (1999). Testing of trends in data unevenly distributed in time. Theoretical and Applied Climatology 64: 151-162.

Lee, T.P., Silberg, S.R. and Bosart, L.F. (1988). A case study of a severe winter storm in the Middle East. Quart J Roy Meteor Soc, 114: 61-90.

Li, Y. (2001). A phase space EOF method and its application to climate diagnosis. Plateau Meteorology, 20(1): 88-93. (in Chinese)

Miller, A.J., Cayan, D.R., Barnett, T.P., Graham, N.E. and Oberhuber, J.M. (1994). The 1976- 1977 climate shift of the Pacific Ocean. Oceanography 7: 21-26.

Mitchell, J.M., Dzerdzeevskii, B., Flohn, H. and Hofmery, W.L. (1966). Climatic change. WMO Tech. Note 79. WMO No. 195. TP-100, Geneva, 79pp.

Namias, J. (1988). Abrupt change in climate regime from summer to fall 1985 and stability in the fall. Meteo Atmos Phys 38: 34-41.

Namias, J. (1990). Basis for prediction of the sharp reversal of climate from autumn to winter 1988-1989. Int J Climatol, 10: 659-678.

Overpeck, J.T. and Cole, J.E. (2006). Abrupt Change in Earth's Climate System. Annual Review of Environment and Resources, 31: 1-31.

Pearson, E.S. and Hartley, H.O. (1958). Biometrika Tables for Statisticians. Cambridge Univ. Press, Cambridge, England, 240pp.

Rieter, E.R. (1975). Handbook for forecasters in the Mediterranean. Technical Report No. 5- 75, Navy Environmental Research and Prediction Facility, Monterey, California 93043, USA.

Schonwiese, C.D. and Rapp, J. (1997). Climate trend atlas of Europe. Based on observations 1891- 1990. Kluwer, Dordrecht, The Netherlands.

Schyfsma, E. (1978). Climate. In: Al-Sayari, S.S., Z. otl, J. (Eds.), Quaternary Period in Saudi Arabia, Vol. 1. Springer, Vienna, New York, pp. 31-44.

Shapiro, R. (1975). Linear filtering. Mathematical Computation, 29: 1094-1097. 
Shmida, A. (1985). Biogeography of the desert floras of the world. In: Hot Deserts. Evenari, M. and I. Noy-Meir and D.W. Goodall (eds.) Ecosystems of the World, Vol. 12a. Hot Deserts and Arid Shrublands, Elsevier Amsterdam. pp. 23-77.

Sneyers, R. (1990). On the statistical analysis of series of observations. World Meteorological Organization (WMO), Technical Note, No. 143, Geneva, 192pp.

Trigo, I.F., Bigg, G.R. and Davis, T.D. (2002). Climatology of cyclogenesis mechanisms in the Mediterranean. Mon Wea Rev 130: 549-569.

Yan, M., Wei, D. and Xuehui, M. (2001). Climate variation in the Sanjiang Plain disturbed by large scale reclamation during the past 45 years. Acta Geographica Sinica, 56(2): 159-170. (in Chinese)

Zhao, F., Xu, Z. and Huang J. (2008). Long-Term Trend and Abrupt Change for Major Climate Variables in the Upper Yellow River Basin. Acta Meteorologica Sinica, 21(2): 204-214. 


\section{التغيرات في درجة حرارة الثتاء للمملكة العربية السعودية}

\section{عبد الرحمن الخلف، و حسني حسانين}

قسم الأرصاد - كلية الأرصاد والبيئة وزراعة الدناطق الجافة، جامعة الدلك عبد العزيز، جدة - المدلكة العربية السعودية

الستخلص. تم تحليل منوسط درجات الحرارة لفصل الثتاء (ديسمبر

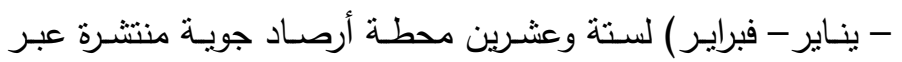

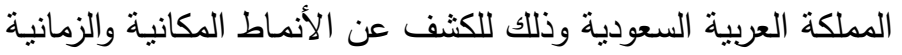

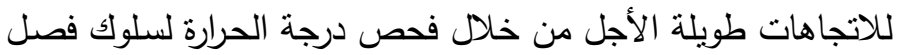

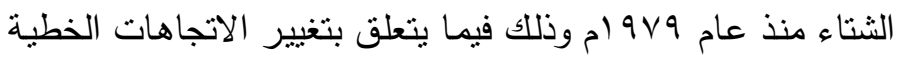

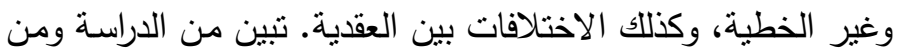

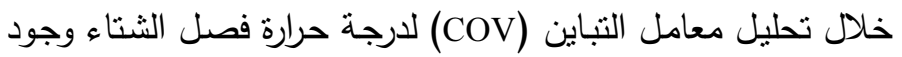

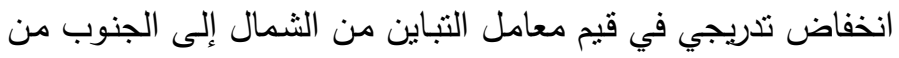

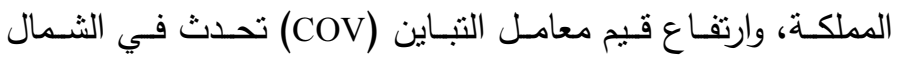

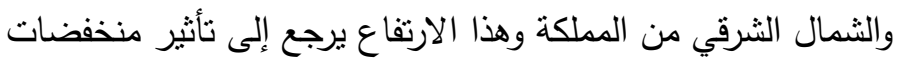

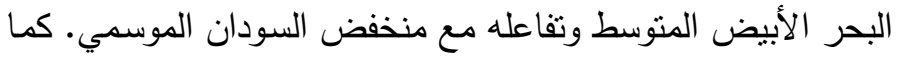

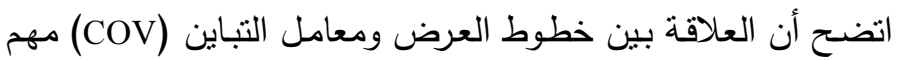

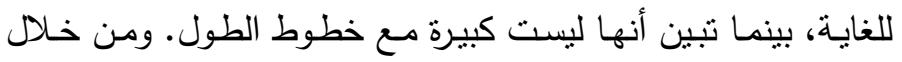
تحليل اختبار رتبة الإحصائية (لمان - كندال) اتضح أنسان الانية الاتجاهات

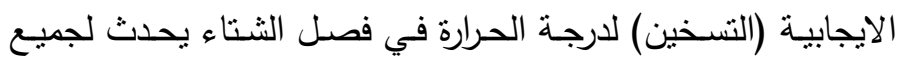

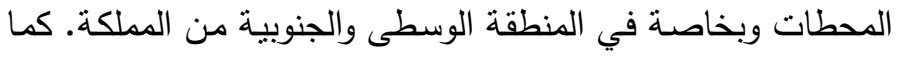

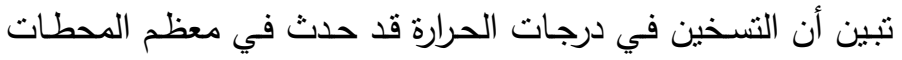

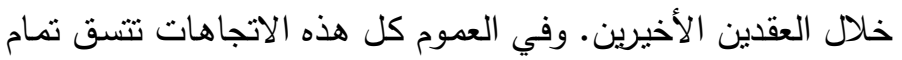
الاتساق مع الاتجاهات في متوسط درجة الحرارة السطحية في العالم.

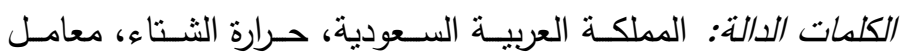

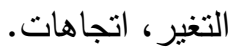

